\title{
Near-Death Experiences, Altered States, and Psi Sensitivity
}

\author{
Richard L. Kohr \\ Pennsylvania Department of Education
}

\begin{abstract}
This investigation compared the frequency of psi experiences, psi-related experiences, mystical states, dream experiences, and a variety of demographic variables for three criterion groups. Comprising the three groups were 358 individuals who had never come close to death, 105 people who claimed to have had a close call with death but without an intense experience associated with it, and 84 individuals whose responses to a questionnaire indicated they had had a neardeath experience (NDE). Analyses revealed that the NDE group manifested a significantly greater incidence of psi and psi-related experiences, dream experiences, and mystical states. The study also reported on an item analysis of NDE characteristics and on an effort to develop an NDE score. The NDE group was further separated into "moderate" and "deep" experiencers based on the NDE score. Comparisons of these two groups resulted in fewer significant differences in psi experiences than in the original three-group analyses.
\end{abstract}

\section{INTRODUCTION}

With the striking popularity of Raymond Moody's (1975, 1977) books on near-death experiences (NDEs), lay audiences and professionals alike have become intrigued with this fascinating aspect of human experience. Many interesting parallels are observed in NDEs and the phenomenology of mystical insight. Among the features of mystical experience outlined by Walter Pahnke and William Richards (1966) that frequently accompany the deeper NDE are ineffability, a transcendence of space and time, deep positive feelings of intense peace and quiet, transciency of the exalted state, a noetic quality of having received deep knowledge or apprehension of reality, and persistent positive changes in attitude and behavior. In addition, various researchers have suggested that transpersonal states facilitate the acquisition of information through psychic mechanisms (e.g., LeShan, 1973). 
Certain features of NDEs also correspond to out-of-body experiences (OBEs), which have a long history in the parapsychological literature (e.g., Crookall, 1970). Charles Tart (1974) presented some interesting illustrations of information acquired paranormally during an $\mathrm{OBE}$. Various observers have advanced the notion that states such as OBEs and transcendent experiences may provide a vehicle for the operation of ESP or psi. Thus, the term psi-conducive state was used by Charles Honorton (1974) in his discussion of hypnosis, meditation, dreams, and psychedelic drugs in promoting paranormal experience.

Kenneth Ring (1980a, 1981) touched upon what he termed a flashforward or possible life preview that sometimes occurs in an NDE. In an investigation of precognitive phenomena associated with especially deep NDEs, Ring (1982) described NDE visions of events involving the percipient ("personal flashforward") at some time following the NDE.

In a medical context, cardiologist Michael Sabom (1982) recently described a series of "autoscopic" surgical experiences in which patients perceived themselves as outside their bodies and able to provide amazingly accurate accounts of actions of medical staff and procedural details of their surgery.

The investigation I am reporting received its impetus from research published by Ring (1979). His findings stimulated me to include a special section on NDEs in a large workbook questionnaire I was preparing for the Association for Research and Enlightenment (A.R.E.), headquartered in Virginia Beach, Virginia. 1 The questionnaire was extensive. Major sections dealt with psi, meditation, dreams, health, and near-death-type experiences. Data collected from a national survey of A.R.E. members during 1980 were reported in summary form by Kohr (1982). The present article reports more extensively on analyses that explored the extent to which individuals claiming to have had NDEs differed from those not having such experiences in terms of dream, meditation, and psi experiences.

\section{SURVEY METHOD}

The survey instrument was a 37-page workbook composed of 221 questions developed from experimental and survey studies conducted by the A.R.E. Research Committee during a five-year period. Contained in the section on death were questions regarding general attitudes toward death and an afterlife, beliefs about reincarnation, and memory patterns interpreted by the respondent as a possible 
previous life. Respondents also answered questions concerning a close encounter with death and whether or not various features of the "core" NDE (Ring, 1979) were present.

The A.R.E. is an organization with a current nationwide membership of more than forty thousand people intrigued by the legacy of the late American psychic Edgar Cayce. This membership can be characterized as having interests in paranormal phenomena, dreams, meditation, holistic health, and other topics related to human potential. The workbook questionnaire was made known to the membership in its monthly newsletter. Throughout 1980 , members interested in participating paid a five-dollar fee to receive a copy of the workbook. Of the approximately 700 workbook questionnaires sent out, 547 were returned. Obviously the respondents represent an atypical population of individuals who are attracted to an organization like the A.R.E. because of their own psi experiences and who are even willing to pay to participate. Despite the necessary constraint on generalizing results from this sample, there is cause for optimism that statistical relationships observed in the data may hold true for samples more representative of the general population. This expectation receives support from the fact that a great deal of correspondence occurred between the correlational results reported by John Palmer (1979) in his 1974 mail survey of Charlottesville townspeople and University of Virginia students regarding psi experiences and those reported by Kohr (1980), who analyzed data from a 1975 survey of the A.R.E. membership using the identical questionnaire.

\section{DEMOGRAPHIC CHARACTERISTICS OF THE SAMPLE}

A geographical breakdown of the respondents revealed a broad national distribution: 27 percent lived in the northeast, 17 percent in the south, 24 percent in the midwest, 12 percent in the southwest, 16 percent in the west coast area, and 3 percent in Canada. The sample was 75 percent female, 98 percent white, and had a mean age of 44 . Of the respondents, 68 percent were married, 14 percent single, and 18 percent widowed or divorced. Educationally, 41 percent were college graduates, while another 39 percent had received some post-high-school education including two-year technical programs, nursing programs, associate degrees, and some college work. In terms of political orientation, 20 percent viewed themselves as conservative, 55 percent as moderate, and 25 percent as liberal. Of the respondents, 31 percent classified their community as a rural or small-town environment, 21 percent as a medium-sized city 
(10 to 100 thousand), 26 percent as a suburb of a medium or large city, and 22 percent as inside a large city (over 100 thousand).

\section{DEFINITION OF GROUPS}

Based on a series of eight questions regarding proximity to death, the respondents were divided into three groups. The first group, referred to as the Non-Experiencing (NE) group, consisted of 358 persons who answered "no" to the question, "Have you ever come very close to death?"

A second group, labeled the Close to Death Only (CD) group, consisted of 105 individuals who indicated they had come close to death; however, they did not meet other criteria indicative of a deeper quality experience associated with the close call. Eightyseven answered "no" to the question, "During your close brush with death did you have a deep, moving personal experience?" Eighteen additional people answered "yes" to this question but failed to experience any of the features of a core NDE (Ring, 1979).

The third group, composed of 84 respondents and referred to as the Experiencing (E) group, indicated they had come close to death, had had a deep, moving personal experience concomitant with the encounter, and claimed to have had at least one of the following six types of experience described by Ring (1979) as constituting the core NDE: (1) a profound sense of peace and contentment, (2) a sense of being detached from the physical body, (3) movement into a "space" between this world and another that seemed to be without dimension, (4) the presence of another being who helped assess one's life and offer a choice of remaining or not, (5) brilliant white or golden light that engulfed one and brought contentment, and (6) unforgettable beauty of colors and/or heavenly music. Relative to the 547 cases in the sample, the NE group represented 65 percent; the $C D$ group, 19 percent; and the $\mathrm{E}$ group, 15 percent.

Most research on the NDE has obtained data from extensive interviews rather than questionnaire methodology. Thus, individuals in this study who are classified as E-group members might not have been similarily classified by the interview technique. However, the internal consistency of the items descriptive of an NDE, as described in the next section, suggests the items were measuring a rather stable phenomenon. 


\section{ITEM ANALYSIS OF THE NDE CHARACTERISTICS}

Respondents having a moving personal experience in conjunction with their close brush indicated whether any of the six core characteristics were part of that experience. Using data from the $84 \mathrm{E}$-group respondents, the six NDE features were analyzed for their scalability. A FORTRAN computer program (Kohr, 1971) was used in estimating internal-consistency reliability (Cronbach, 1951) and distributional characteristics. A total score ranging from one (answered "yes" to only one of the six questions) to six (endorsed all six items) was produced under the assumption that a higher score would be indicative of a more "profound" experience. The correlation of each item to the total score was estimated using Sten Henrysson's (1963) adjustment, thereby removing the excessive influence of an individual item on the total score when the number of items is small. Table 1 displays the NDE characteristics and presents the item-analysis results.

\section{Table 1}

Item Analysis of NDE Characteristics 1

Near-Death Experience Characteristics $\begin{gathered}\text { Percent } \\ \text { Responding } \\ \text { "Yes" }\end{gathered} \quad \begin{array}{r}\text { Adjusted } \\ \text { Item-Total } \\ \text { Correlation }\end{array}$

1. Experienced a feeling of profound peace and contentment, so deeply moving that words fail to come close to describing the experience.

2. Experienced a sense of being detached from the physical body, whether or not you could actually "see" the body.

3. Experienced a movement in to a "space" between this world and the next which seemed to be very peaceful and without dimension. 


\begin{tabular}{lcr} 
Near-Death Experience Characteristics & $\begin{array}{c}\text { Percent } \\
\text { Responding } \\
\text { "Yes" }\end{array}$ & $\begin{array}{r}\text { Adjusted } \\
\text { Item-Total } \\
\text { Correlation }\end{array}$ \\
\hline
\end{tabular}

4. Sensed a presence of another being which helped me assess my life and offered a choice of whether to $36 \%$ continue in this experience or go back.

5. Saw a brilliant white or golden light which was restful, comforting, and $37 \%$ of extraordinary beauty.

6. Found myself in a world of exquisite beauty with unforgettable colors $26 \%$ .58 and/or "heavenly" music.

Coefficient Alpha estimate of internal-consistency reliability $=.62$

Distributional Characteristics $\underline{\text { Summary Statistics }}$ $\frac{\text { NDE Score }}{1} \frac{\text { Number }}{20} \frac{\text { Percent }}{24 \%}$

$\begin{array}{rrr}2 & 22 & 26 \% \\ 3 & 13 & 15 \% \\ 4 & 10 & 12 \% \\ 5 & 11 & 13 \% \\ 6 & \frac{8}{84} & \frac{10 \%}{100 \%}\end{array}$

Mean $=2.93$

$\underset{\text { Deviation }}{\text { Standard }}=1.65$

Skewness $=0.49$

Kurtosis $=-1.01$

1Respondents answered "yes" or "no" as to whether each item represented part of their near-death experience. 
Experiencing a profound peace (item 1) and a sense of being detached from the physical body (item 2) were the most prevalent features claimed by the $E$ respondents. Half claimed to experience a dimensionless space (item 3 ), while approximately a third sensed the presence of another being (item 4) or saw a brilliant light of extraordinary beauty (item 5). Lastly, about a quarter of the E group perceived themselves to be in a world of exquisite beauty and/or music (item 6). The pattern of decreasing incidence across items roughly approximates the one described by Ring (1979). The higher incidence of experience observed in the present study is likely due to different question phrasing, the lack of an interview, which permits appropriate follow-up questioning to rule out missinterpretations, and the fact that the percentages are inflated by using just those respondents who displayed one or more of the core characteristics.

All items except the first (feeling profound peace) revealed a substantial adjusted item-total correlation with the total NDE score. The internal consistency (Coefficient Alpha of .62) is quite substantial for a short scale of only six items and provides technical support for deriving a total score as a reliable indicator of the strength or depth of an NDE. Of course further research is necessary to provide evidence regarding the degree of stability and validity of this short measure. It might be mentioned that a recent effort by Bruce Greyson (1983a) to develop an NDE scale to discriminate accurately between individuals having an NDE and those having symptoms of other stress-related syndromes yielded quite promising evidence as a reliable and valid screening device.

Table 1 also reveals the distributional properties of the NDE scores attained by the $\mathrm{E}$ group. Twenty respondents ( 24 percent) experienced only one of the six core features. That would represent only a relatively "light" experience, which, considering Ring's (1980a) stage concept, should be found in an item typical of a less profound experience. An examination of the response patterns of those individuals who claimed only one feature revealed 13 indicated their single experience was item one (profound peace) and 4 claimed item two (sense of detachment from body). That is consistent with an "early stage" NDE. At the other end of the continuum, 8 individuals ( 10 percent) claimed all six characteristics (NDE score of 6 ), which would suggest a profound experience. If one were to regard scores of one or two as a relatively light NDE, scores of three and four a moderately profound NDE, and five or six a deeply profound experience, then 50 percent would fall into the "light" category, 
27 percent in the "moderate" category, and 23 percent in the "deep" category.

\section{BACKGROUND CHARACTERISTICS OF COMPARISON GROUPS}

Table 2 contains a brief statistical summary of the comparison groups.

Table 2

Summary of Comparison Group Demographic Characteristics and Attitudes

\begin{tabular}{|c|c|c|c|c|c|c|}
\hline \multirow[b]{2}{*}{ Characteristics } & \multicolumn{2}{|c|}{$\begin{array}{l}\text { NE Group } \\
(N=358)\end{array}$} & \multicolumn{2}{|c|}{$\begin{array}{l}\text { CD Group } \\
(\mathrm{N}=105)\end{array}$} & \multicolumn{2}{|c|}{$\begin{array}{l}\text { E Group } \\
(N=84)\end{array}$} \\
\hline & Mean & SD & Mean & SD & Mean & SD \\
\hline Age & 43.79 & 12.74 & 44.44 & 12.89 & $47.37^{a}$ & 13.54 \\
\hline Marital Status 1 & 0.72 & 0.45 & $0.58^{\mathrm{a}}$ & 0.49 & 0.66 & 0.48 \\
\hline Religious Affiliation ${ }^{2}$ & 0.87 & 0.34 & 0.83 & 0.38 & 0.81 & 0.40 \\
\hline $\operatorname{Sex}^{3}$ & $0.79^{\mathrm{b}}$ & 0.41 & 0.60 & 0.49 & $0.80^{\mathrm{b}}$ & 0.40 \\
\hline Education & 4.38 & 1.18 & 4.45 & 1.22 & 4.26 & 1.13 \\
\hline Community Type (Pop. Density) & 3.21 & 1.35 & 3.25 & 1.38 & 3.26 & 1.43 \\
\hline Political Orientation & 3.07 & 0.80 & 3.05 & 0.80 & 3.08 & 0.95 \\
\hline Religiosity $^{*}$ & 1.92 & 0.81 & 1.75 & 0.85 & $1.67^{\mathrm{a}}$ & 0.89 \\
\hline Thinking about own death ${ }^{*}$ & 3.36 & 1.12 & 3.25 & 1.34 & $3.02^{\mathrm{a}}$ & 1.30 \\
\hline Anxiety concerning own death & 1.61 & 0.66 & 1.66 & 0.83 & 1.52 & 0.65 \\
\hline Anxiety about death of loved ones & 2.40 & 1.00 & 2.24 & 1.00 & $2.14^{\mathrm{a}}$ & 0.97 \\
\hline
\end{tabular}

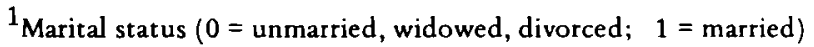

${ }^{2}$ Religious affiliation ( $0=$ non-conventional, $1=$ conventional)

${ }^{3}$ Sex $(0=$ male, $1=$ female $)$

* Signifies that a low score represents a greater degree of the characteristic.

andicates the mean score is significantly $(p<.05)$ different from that observed for the NE Group.

bIndicates the mean score is significantly $(p<.05)$ different from that observed for the CD Group.

The groups did not differ significantly on religious affiliation, educational level, type of community in which they live, or political orientation. Each group tended toward conventional religious affiliation (i.e., Protestant, Catholic, Jewish, or non-denominational Christian), typical educational level reached was post-high-school 
training, community type was generally defined as a medium-sized city, and political orientation tended toward moderate (on a fivepoint scale ranging from very conservative to very liberal). The finding of no significant differences on religious affiliation replicates Ring's (1980a, 1980b) observation. Ring (1980a) also reported no differences on a social-class index.

Statistically significant differences were found for age, marital status, sex, and religiosity. The E group was somewhat older (by nearly four years) than the NE group. The proportion of married people was significantly less for the $C D$ group than for the NE group. The $C D$ group also contained a lower proportion of females than the other two groups. Of particular interest is the significantly greater religiosity score for the E group than for the NE group. The religiosity item asked participants how religious they considered themselves to be. The answer choices were on a four-point scale including very religious (scored one), moderately religious, slightly religious, and not at all religious (scored four). Ring (1980a, 1980b) reported that "core" experiencers became more religious following their NDE than non-core experiencers. It is possible that the greater religiosity self-appraisal of the present study's $E$ group reflects such a shift subsequent to their experience; however, there is no way of substantiating that.

Since the NDE literature reports a reduced fear of one's own death following an NDE, it was anticipated that the E group would reveal less perceived anxiety than the $\mathrm{CD}$ and NE groups. Although the mean score was in the expected direction, it failed to reach statistical significance. A recent study by Keith Wood and Paul Robinson (1982) found that fear of death was slightly lower for highly self-actualized persons than those of lower self-actualization. They suggested that actualization may be "the degree to which the individual is satisfied with who he is as a human being ... and fear of death is the degree to which death is integrated into the individual's personal construct system" (pp. 241-242). Possibly the E-group members have integrated personal death more extensively than those comprising the other comparison groups, although as one reenters life and reestablishes goals there may be a degree of "unfinished business" that clouds one's readiness to accept death.

Although the groups did not differ with respect to perceived anxiety regarding one's own death, the E group did manifest significantly more anxiety concerning a loved one's death and more frequent thoughts about their own death than members of the NE group. The CD group did not differ from either the NE or E groups on any attitude-toward-death item. 


\section{NDEs AND PSI AND PSI-RELATED EXPERIENCES}

Table 3 presents the statistical summary for the three comparison groups in terms of psi and psi-related experiences. The direction of scoring for all types of psi and psi-related experiences is that the higher the numerical value, the greater the incidence of the experience. The experiences are organized in Table 3 in terms of psi perception, psychokinesis and healing, and psi-related and mystical experiences. This structure is similar to the one devised by Palmer in his 1979 survey of psi experiences and subsequently by Kohr (1980). Instead of including psychokinesis (PK) under psi, it is placed in a separate category along with healing, which some researchers have suggested is a special case of PK. Psi-related experiences follow Palmer's scheme, which includes auras, apparitions, communication with an entity (mediumship or spirit communication), dream interaction, and out-of-body experiences. Mystical experiences are categorized separately although transpersonal experiences are sometimes included among psi-related experiences. The exact wording of the questions measuring psi and psi-related experiences is presented in the Appendix.

Following significant results from analysis of variance, individual t-tests were performed. As a protection against Type I error when sample sizes are unequal and variances likely to differ, the BehrensFisher $t$ was calculated along with Welch's adjustment for degrees of freedom (Kohr and Games, 1977). The analysis revealed little or no differences between the $C D$ and NE groups, but many interesting differences between the $\mathrm{E}$ group and the other two groups. In all instances the $\mathrm{E}$ group showed a significantly greater tendency to report psi or psi-related experiences such as general ESP in both the waking and the dream state, $\mathrm{PK}$, auras, apparitions, and OBEs.

In addition to each type of psi and psi-related experience, several composite scores were constructed. The total number of types of psi/psi-related experience was found simply by counting the number of different types of experience claimed by the individual respondent. Since there were six response categories (scored one to six), ranging from "never" to "more than 10 times," the possible score range was 10 to 60 . Note that a score of 10 denotes an absence of psi experience as indicated by a "never" response to each of the ten types of experience. Not surprisingly, the composite scores were found to be significantly higher for the E group than for the other comparison groups.

In addition to questions concerning the frequency of psi and psi- 
Table 3

\section{Summary of Comparison Group Means and Standard Deviations for Psi and Psi-Related Experiences}

\begin{tabular}{|c|c|c|c|c|c|c|}
\hline \multirow[b]{2}{*}{ Psi and Psi-Related Experiences } & \multicolumn{2}{|c|}{$\begin{array}{l}\text { NE Group } \\
(\mathrm{N}=358)\end{array}$} & \multicolumn{2}{|c|}{$\begin{array}{l}\text { CD Group } \\
(\mathrm{N}=105)\end{array}$} & \multicolumn{2}{|c|}{$\begin{array}{l}\text { E Group } \\
(\mathbf{N}=84)\end{array}$} \\
\hline & Mean & SD & Mean & SD & Mean & SD \\
\hline \multicolumn{7}{|l|}{ Psi Perception } \\
\hline Psi dream & 2.84 & 1.89 & 2.94 & 1.92 & $3.81^{a, b}$ & 2.10 \\
\hline Waking psi & 3.42 & 2.02 & $3.88^{\mathrm{a}}$ & 2.01 & $4.54^{\mathrm{a}, \mathrm{b}}$ & 1.85 \\
\hline Telepathic communication & 3.84 & 2.12 & $4.33^{\mathrm{a}}$ & 1.90 & $4.89^{\mathrm{a}, \mathrm{b}}$ & 1.84 \\
\hline \multicolumn{7}{|l|}{ Psychokinesis and Healing } \\
\hline Psychokinesis & 1.28 & 0.80 & 1.50 & 1.25 & $1.83^{\mathrm{a}}$ & 1.55 \\
\hline Healing & 3.12 & 1.96 & 3.18 & 1.94 & $4.40^{\mathrm{a}, \mathrm{b}}$ & 1.92 \\
\hline Healing (control over) & 2.18 & 1.17 & 2.26 & 1.22 & $2.60^{\mathrm{a}}$ & 1.24 \\
\hline \multicolumn{7}{|l|}{ Psi-Related Experiences } \\
\hline Seeing auras & 2.56 & 1.94 & 2.61 & 1.97 & $3.23^{\mathrm{a}, \mathrm{b}}$ & 2.04 \\
\hline Apparitions & 2.43 & 1.66 & $2.83^{\mathrm{a}}$ & 1.88 & $3.66^{a, b}$ & 1.99 \\
\hline Communication with entity & 1.65 & 1.38 & 1.86 & 1.67 & $2.51^{\mathrm{a}, \mathrm{b}}$ & 2.02 \\
\hline Dream interaction & 1.50 & 0.96 & 1.72 & 1.24 & $2.26^{a, b}$ & 1.67 \\
\hline Out-of-body experiences & 2.48 & 1.74 & 2.54 & 1.74 & $3.70^{\mathrm{a}, \mathrm{b}}$ & 1.85 \\
\hline Out-of-body (control over) & 1.41 & 0.86 & 1.43 & 0.88 & $1.72^{\mathrm{a}, \mathrm{b}}$ & 1.05 \\
\hline $\begin{array}{l}\text { Composite: Types of Psi and } \\
\text { Psi-Related Experiences }\end{array}$ & 5.51 & 2.23 & 5.95 & 2.13 & $7.20^{\mathrm{a}, \mathrm{b}}$ & 2.10 \\
\hline $\begin{array}{l}\text { Composite: Number of Psi and } \\
\text { Psi-Related Experiences }\end{array}$ & 25.00 & 9.13 & $27.38^{\mathrm{a}}$ & 10.30 & $34.80^{\mathrm{a}, \mathrm{b}}$ & 11.04 \\
\hline \multicolumn{7}{|l|}{ Mystical Experience } \\
\hline Mystical experiences & 3.05 & 1.93 & 3.41 & 1.75 & $4.13^{a, b}$ & 1.77 \\
\hline Mystical experience composite & 2.52 & 1.14 & 2.84 & 1.02 & $3.27^{\mathrm{a}, \mathrm{b}}$ & 0.84 \\
\hline
\end{tabular}

alndicates the mean score is significantly $(p<.05)$ different from that observed for the NE Group.

blndicates the mean score is significantly $(\mathrm{p}<$.05) different from that observed for the CD Group.

related experiences, respondents were asked, "To what extent are you able to produce this experience voluntarily?" Analyses of that question revealed significantly greater control perceived by E-group members in healing and OBEs. These results are included in Table 3. Group differences in the perceived ability to control other forms of psi/psi-related experiences were not observed and in the interest of brevity are not presented. 
Mystical states occurred more frequently for the E group than for the NE or CD groups. A composite mystical-experience score was also computed by combining several items pertaining to whether the experience included an encounter with a spiritual being or a transcendent quality within oneself. Here again, the $\mathrm{E}$ group displayed a significantly higher score.

Up to this point analyses have focused on differentiating among three criterion groups. The group of respondents reporting one or more features of a core NDE (E group) has clearly demonstrated a higher incidence of each type of psi or psi-related experience. As suggested earlier, an E-group member with a high NDE score may reflect a "deeper" level experience than the person with a low score. The most extreme difference in this way of assessing depth would contrast the experience of respondents claiming just one NDE feature with those claiming each of the six features measured in the questionnaire. An interesting question is whether the frequency of psi and psi-related experiences is related to NDE depth. In order to have sufficient cases to examine this possibility, respondents claiming one to three features $(n=55)$ were compared with those reporting four to six characteristics $(n=29)$. For convenience, the high scorers are referred to as the "deep" experiencers and the low scorers as "moderate" experiencers.

Statistically significant results were observed for only a few variables. The "deep" group reported significantly more types of psi-related experiences (3.90 to 3.11), a greater number of psirelated experiences (18.48 to 13.66$)$, and a larger number of mystical experiences (3.59 to 3.11 ).

Clearly, the "deep" vs "moderate" NDE comparisons turned up far fewer significant differences in psi and psi-related experiences than found in the analyses contrasting the NE, CD, and E groups. Since the "deep-moderate" analyses involved fewer cases, the lower incidence of significant results could be attributed to the reduction of sample size. Relevant to this concern is Jacob Cohen's (1969) concept of "effect size." When mean scores are statistically compared Cohen defines effect size ( $d$ index) in terms of standard units, i.e., the size of the difference between means relative to the common standard deviation. When applied to the present data, it was found that the $d$ values were indeed smaller for the "deep-moderate" comparisons than for the E-group-non-E-group comparisions. This finding supports the conclusion that psi experience is more strongly related to having an NDE vs. not having one than the NDE depth. 


\section{NDEs AND VARIOUS ALTERED STATES}

Table 4 displays the statistical results for an openness to dreams, past-life memories, and meditative practices and experiences. The asterisk found next to the descriptors of most experiences signifies that the direction of scoring is reversed, i.e., the lower the score, the greater quantity or perceived quality of something.

Scaled scores were also computed for most of the meditation and dream variables. The psychometric quality of these constructed scores was judged to be satisfactory on the basis of high internal-consistency reliability coefficients.

The $\mathrm{E}$ group demonstrated a greater degree of openness toward dream states than the $N E$ and $C D$ groups in nearly each category. Not only did members of the $\mathbf{E}$ group tend to report more color, types and number of sense modalities, and unusual dream states, but greater intentionality in recalling dreams and a greater tendency to regard them as helpful.

The incidence of memories interpreted as past-life recall was also greater for the $\mathrm{E}$ group. Likewise, the $\mathrm{E}$ group excelled on a composite past-life recall variable comprised of several items dealing with awareness of names, places, and events from apparently out of the past that were unknown prior to the emergence of the "memory."

With respect to meditation, the E group reported greater intensity, meaning, and positive quality of personal meditation sessions, greater consistency in maintaining a meditation schedule, more days per week engaging in meditation, and a more positive influence of meditation on daily life.

\section{DISCUSSION}

The findings of this study are correlational in nature, and definite causal connections cannot be established. It is interesting to speculate on whether $\mathrm{E}$ persons report more psi experiences, more frequent and unusual dream states, and more positive meditation experiences because of their intense experience concomitant with a close brush with death. Or, perhaps, are psychically sensitive individuals, when confronted with a near-death situation, more open to experiencing a transcendent state? The potential of psychically sensitive individuals having greater receptivity to the unconscious and to nonrational material was discussed by Palmer (1979) in his effort to explain the relationship between dreaming, mystical states, and psi experience. Palmer noted that a high frequency of dream recall and 
Table 4

Summary of Comparison Group Means and Standard Deviations
for Dream States, Past-Life Recall, and Meditation

\begin{tabular}{|c|c|c|c|c|c|c|}
\hline \multirow[b]{2}{*}{ Experiences } & \multicolumn{2}{|c|}{$\begin{array}{l}\text { NE Group } \\
(\mathrm{N}=358)\end{array}$} & \multicolumn{2}{|c|}{$\begin{array}{l}\text { CD Group } \\
(\mathrm{N}=105)\end{array}$} & \multicolumn{2}{|c|}{$\begin{array}{l}\text { E Group } \\
(N=84)\end{array}$} \\
\hline & Mean & SD & Mean & SD & Mean & SD \\
\hline \multicolumn{7}{|l|}{ Dream States and Openness to Dreams } \\
\hline Frequency of dreaming in color ${ }^{*}$ & 2.89 & 1.50 & 3.01 & 1.51 & $2.45^{\mathrm{a}, \mathrm{b}}$ & 1.44 \\
\hline Perceived helpfulness of dreams ${ }^{*}$ & 2.44 & 1.13 & 2.45 & 1.13 & $1.99^{a, b}$ & 0.98 \\
\hline $\begin{array}{l}\text { Types of sense modalities } \\
\text { experienced in dreams }\end{array}$ & 6.05 & 2.06 & 6.13 & 1.96 & $7.01^{a, b}$ & 1.75 \\
\hline $\begin{array}{l}\text { Total number of sense modalities } \\
\text { experienced in dreams }\end{array}$ & 27.49 & 6.10 & 26.85 & 6.13 & $24.76^{a, b}$ & 5.13 \\
\hline Intentionality of dream recall & 13.47 & 1.80 & 13.11 & 2.14 & $13.71^{b}$ & 1.76 \\
\hline $\begin{array}{l}\text { Frequency of unusual dream } \\
\text { states (lucidity, vibrations) }\end{array}$ & 9.97 & 2.32 & 10.29 & 2.29 & $9.30^{\mathrm{a}, \mathrm{b}}$ & 2.41 \\
\hline Lucid-type dreams ${ }^{*}$ & 3.24 & 1.09 & 3.23 & 1.15 & 3.08 & 1.11 \\
\hline Strong vibrations during sleep ${ }^{*}$ & 3.85 & 1.35 & 4.10 & 1.15 & $3.34^{\mathrm{a}, \mathrm{b}}$ & 1.37 \\
\hline Volitional control over dream ${ }^{*}$ & 3.05 & 0.92 & 2.95 & 0.96 & 3.04 & 0.98 \\
\hline \multicolumn{7}{|l|}{ Past-Life Recall } \\
\hline Previous-life memory ${ }^{*}$ & 1.33 & 0.47 & 1.30 & 0.46 & $1.10^{\mathrm{a}, \mathrm{b}}$ & 0.30 \\
\hline Number of memory experiences & 1.93 & 1.10 & 2.03 & 1.17 & $2.47^{\mathrm{a}, \mathrm{b}}$ & 1.32 \\
\hline Composite past-life recall & 1.96 & 0.86 & 2.16 & 0.99 & $2.58^{\mathrm{a}, \mathrm{b}}$ & 0.87 \\
\hline \multicolumn{7}{|l|}{ Meditative Practice } \\
\hline Consistency in meditation ${ }^{*}$ & 2.19 & 0.73 & 2.33 & 0.76 & $2.05^{b}$ & 0.63 \\
\hline Days per week meditate ${ }^{*}$ & 2.13 & 1.06 & 2.20 & 1.12 & $1.83^{\mathrm{a}, \mathrm{b}}$ & 1.00 \\
\hline Perceived effect on life ${ }^{*}$ & 1.49 & 0.78 & 1.62 & 0.88 & $1.31^{\mathrm{a}, \mathrm{b}}$ & 0.69 \\
\hline Intensity of meditative experience & 12.50 & 2.62 & 12.52 & 2.46 & $11.01^{\mathrm{a}, \mathrm{b}}$ & 2.71 \\
\hline Physical sensations during med. & 8.34 & 2.21 & 8.76 & 2.40 & $7.45^{\mathrm{a}, \mathrm{b}}$ & 2.50 \\
\hline Sense of meaning in meditation ${ }^{*}$ & 6.14 & 1.63 & 6.20 & 1.71 & $5.25^{\mathrm{a}, \mathrm{b}}$ & 1.46 \\
\hline Perceived positiveness ${ }^{*}$ & 31.92 & 5.36 & 32.36 & 5.05 & $28.61^{a, b}$ & 5.43 \\
\hline $\begin{array}{l}\text { Composite helpfulness of } \\
\text { meditation }\end{array}$ & 18.00 & 6.26 & 18.76 & 6.97 & $15.21^{a, b}$ & 5.30 \\
\hline Perceived quality of meditation & 3.41 & 1.01 & 3.38 & 0.92 & $3.71^{\mathrm{a}, \mathrm{b}}$ & 1.00 \\
\hline
\end{tabular}

* Signifies that a low score represents a greater degree of the characteristic.

andicates the mean score is significantly $(p<.05)$ different from that observed for the NE Group.

bIndicates the mean score is significantly $(p<.05)$ different from that observed for the CD Group. 
a tendency toward lucid dreaming were indicators of the "degree to which the conscious mind is capable of gaining access to the content of the unconscious mind" (p. 248). He also suggested that mystical experience may reflect availability of the unconscious in the waking state. Palmer (1979) maintained that sensitivity to psi, resulting from accessibility to unconscious material, supported the notion that psi capabilities are "latent in the unconscious mind and potentially available to those who can break through the repressive mechanisms (whatever their basis) that ordinarily prevent them from reaching consciousness" (p. 248). A study by Kohr (1980) confirmed Palmer's results and offered evidence of a general psi-sensitivity trait. This interconnectedness of psi and the main features of the core NDE was alluded to by Ring (1980a) when he proposed that the essential properties of the core NDE "are not unique to near-death states but are potentially available to anyone who learns to operate his consciousness independently of the physical body" (p. 234).

A study conducted by Eugene Thomas, Pamela Cooper, and David Suscovich (1982) found that individuals reporting an NDE were more likely to report having intense spiritual experiences as well. Although they entertained the possibility of NDEs rendering subsequent transcendent states more likely, they preferred to interpret the statistical relationship as reflecting "differences in personality traits or cognitive style that underlies the perception and recall of both near-death and intense spiritual-type experiences" (p. 241). According to Abraham Maslow (1971) an individual's capacity to experience transcendent states depends on a quality of openness that permits them to occur. He argued that constricted personalities, such as those with obsessive-compulsive tendencies, tend to block such "peak" experiences.

Evidence of psi susceptability following an NDE was recently gathered by Greyson (1983b). He found a significantly greater incidence of reported psi and psi-related experiences after the NDE than before. These included the same psi and psi-related experiences described in this investigation, as well as mystical states, lucid dreams, meditation practices, and efforts to analyze dreams for insight. While the results are certainly suggestive of a tendency toward such experiences subsequent to the NDE, Greyson rightfully articulates several viable alternative interpretations that are also consistent with the data. According to Greyson, the NDE may simply have enhanced the individual's awareness of the psi abilities already possessed. Secondly, since data were collected after-the-fact rather than longitudinally, a recall bias may be operating whereby the individual 
considers the NDE as a major life event and attributes exaggerated changes in personality or psi abilities to the ecstatic experience. A third explanation suggested by Greyson is that since the data are based on unverified self-reports, it could be that a delusional belief in one's psi abilities springs from such an overpowering experience as an NDE. Fourth, Greyson pointed out that some underlying third factor may have given rise to the NDE and was also responsible for the subsequent increase in psi experiences.

Evidence of an NDE's potential for releasing subsequent psi experiences is provided by Sabom's (1982) research. He found three cases in which an NDE apparently led to spontaneous autoscopic (out-of-body) experiences. In each instance the individual had no recall of such experiences prior to his or her NDE. One person reported she learned to go out of her body at will to check on things of concern to her. These purposeful excursions permitted her to look in on her infant son in another room or see whether the doors and windows were locked for the night.

As with most non-experimental research, the causal network is difficult to unravel. While we may search for the best explanation, it is certainly possible for several of the interpretations advanced above to have merit.

Palmer (1979) recognized that dream study and meditation represented a quest for deeper self-insight and proposed that psi experiences often served as a stimulus to such activities. It seems equally likely that an NDE could intensify this sense of quest and result in a similar pursuit of self-understanding.

It is interesting to note that a variety of studies have revealed linkages among psi, transcendent states, psi-related experiences, and NDEs. At this stage of research, longitudinal data, although extremely difficult to collect, are needed if we are to trace the manner in which NDEs, spiritual and "growth" practices, attitudes, and peak experiences influence one another.

\section{NOTE}

1. The Association for Research and Enlightenment, Dr. Charles Thomas Cayce, President, maintains a Research Committee consisting of the following members: Dr. Robert Jeffries (University of Bridgeport), Dr. Robert L. Van de Castle (University of Virginia), Dr. Henry Reed (independent consultant, Virginia Beach, Va.), Dr. Richard Kohr (Pennsylvania 
Department of Education), and Dr. E. Douglas Dean (independent consultant, Princton, N.J.).

\section{REFERENCES}

Cohen, J. Statistical Power Analysis for the Behavioral Sciences. New York: Academic Press, 1969.

Cronbach, L.J. Coefficient alpha and the internal structure of tests. Psychometrika, 1951, 16, 297-334.

Crookall, R. Out-of-the-Body Experiences: A Fourth Analysis. Secaucus, N.J.: Citadel Press, 1970.

Greyson, B. The near-death experience scale: construction, reliability and validity. Journal of Nervous and Mental Disease, 1983a, $171,369-375$.

Greyson, B. Increase in psychic phenomena following near-death experiences. Theta, 1983b, 11, 26-29.

Henrysson, S. Correction of item-total correlations in item analysis. Psychometrika, 1963, 27, 419-424.

Honorton, C. Psi-conducive states of awareness. In E. Mitchell (Ed.), Psychic Exploration: A Challenge for Science. New York: Putnam, 1974, 616-638.

Kohr, R.L. An item analysis and scoring program for summated rating scales. Educational and Psychological Measurement, 1971, $31,769-770$.

Kohr, R.L. A survey of psi experiences among members of a special population. Journal of the American Society for Psychical Research, 1980, 74, 395-411.

Kohr, R.L. Near-death experience and its relationship to psi and various altered states. Theta, 1982, 10, 50-53.

Kohr, R.L., and Games, P.A. Testing complex a priori contrasts on means from independent samples. Journal of Educational Statistics, 1977, 2, 207-216.

LeShan, L. The Medium, the Mystic and the Physicist. New York: Viking, 1973.

Maslow, A.H. The Farther Reaches of Human Nature. New York: Viking, 1971.

Moody, R.A. Life After Life. Covington, Ga.: Mockingbird, 1975. Moody, R.A. Reflections on Life After Life. New York: Bantam, 1977.

Pahnke, W., and Richards, W. Implications of LSD and experimental mysticism. Journal of Religion and Health, 1966, 5, 175-208. 
Palmer, J.A. A community mail survey of psychic experiences. Journal of the American Society for Psychical Research, 1979, 73, 221-251.

Ring, K. Further studies of the near-death experience. Theta, 1979, 7, 1-3.

Ring, K. Life at Death. New York: Coward, McCann and Geoghegan, 1980a.

Ring, K. Religious aspects of near-death experiences: some research findings and their implications. Journal of the Academy of Religion and Psychical Research, 1980b, 3, 105-114.

Ring, K. Paranormal and other non-ordinary aspects of near-death experiences: implications for a new paradigm. Essence, 1981, $5,33-51$.

Ring, K. Precognitive and prophetic visions in near-death experiences. Anabiosis, 1982, 2, 47-74.

Sabom, M.B. Recollections of Death. New York: Harper \& Row, 1982.

Tart, C.T. Out-of-the-body experiences. In E. Mitchell (Ed.), Psychic Exploration: A Challenge for Science. New York: Putnam, 1974, 349-373.

Thomas, L.E., Cooper, P.E., and Suscovich, D.J. Incidence of neardeath and intense spiritual experiences in an intergenerational sample: an interpretation. Omega, 1982, 13, 35-41.

Wood, K., and Robinson, P.J. Actualization and the fear of death: retesting an existential hypothesis. Essence, 1982, 6, 235-242.

\section{APPENDIX}

\section{SURVEY QUESTIONS ON PSI AND PSI-RELATED EXPERIENCES}

The portion of the workbook questionnaire dealing with psi experience presented a brief description of each type of experience followed by two questions regarding the frequency of the experience and degree of control one could exert over the experience. These two questions were phrased as follows:

How many times have you had an experience of this type?

1 Never

2 One or two times

3 Three or four times
4 Five or six times

5 Seven to ten times

6 More than ten times 
To what extent are you able to produce this type of experience voluntarily?

1 I have no control over this type of experience

2 About 10 percent of the times I have tried
3 About half of the times I have tried

4 Almost every time I try

\section{DESCRIPTIONS OF EACH TYPE OF EXPERIENCE}

\section{Psi-Perception Experiences}

A dream which matched in detail an event that occurred before, during, or after your dream, and which you did not know about or did not expect at the time of the dream.

While awake, having a strong feeling, impression, or "vision" that a previously unexpected event had happened, was happening, or was going to happen, and later learning that you were right. Transmission of thoughts from one person to another without the use of sensory perception and without expecting to have contact with that person.

\section{Psychokinesis and Healing Experiences}

The movement of an object originating from no "natural" or physical means of motion that you could discover. This would include inexplicable movement, motion or breakage of objects, cessation of function (such as stoppage of clocks).

The restoration to a balanced physical or emotional condition through prayer, laying on of hands, or other "spiritual" technique.

\section{Psi-Related Experiences}

Seeing a light around or about a person's head, shoulders, hands, or body, which was not due to "normal" or "natural" causes.

While awake, having a vivid impression of seeing, hearing, or being touched by another being, which, as far as you could tell, was not due to any external physical or "natural" cause. (Please do not include here experiences of the Christ or other religious figures.)

Experiencing a "communication" with an entity believed to be dead or apparently controlled or "possessed" by a "spirit." 
This type of experience would include communication by hearing a spirit's voice, having the spirit speak through you by controlling your voice, or by controlling your handwriting (automatic writing). A dream in which you saw and interacted with someone who reported to you later a very similar or identical dream with you in it.

An experience in which you felt that "you" were located "outside" or "away from" your physical body; that is, the feeling that your consciousness, mind, or center of awareness was at a different place than your physical body.

Two additional questions concerning the OBE described above were as follows:

In how many of these experiences did you "see" your physical body while "outside" of it?

In how many of these experiences did you get information about previously unknown places or events that later proved to be accurate?

\section{Mystical Experiences}

A profound and deeply moving sense of communication, unity and oneness with all of nature, creation, or God. Mystical states are so intense that words cannot express the grandness, peace, and beauty of the experience.

Two additional questions on mystical experience were asked if the respondent claimed to have had this type of experience.

In your mystical experiences have you ever felt you "met" or saw the actual "person" of God, Jesus, or other spiritual "masters"?

In your mystical experiences have you ever felt you experienced or "met" God within yourself, that is, your own soul, or individual spirit or divine self?

Answer choices to these latter two questions were "yes" or "no."

Requests for reprints to:

Dr. Richard L. Kohr

500 Winand Drive

Harrisburg, Pennsylvania 17109 